\title{
Generation and identification of a thyroid cancer cell line with stable expression of CCDC67 and luciferase reporter genes
}

\author{
LELE ZHANG $^{1,2}$, LONGLONG WANG ${ }^{1,2}$, MENGYUAN LEI $^{1,2}$, RUNSHENG MA $^{1,2}$,

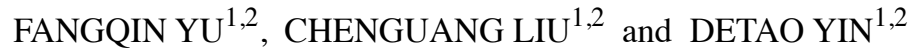 \\ ${ }^{1}$ Department of Thyroid Surgery, The First Affiliated Hospital of Zhengzhou University, Zhengzhou, Henan 450052; \\ ${ }^{2}$ Department of Thyroid Surgery, Key Discipline Laboratory of Clinical Medicine of Henan, \\ Zhengzhou, Henan 450050, P.R. China
}

Received December 8, 2018; Accepted July 9, 2019

DOI: $10.3892 / 01.2019 .10839$

\begin{abstract}
Coiled-coil domain containing 67 (CCDC67) gene is a tumor suppressor gene that exhibits a significant inhibitory effect on a variety of tumors. Our previous study demonstrated that the upregulation of CCDC67 gene in TPC-1 cells inhibited cell proliferation, migration and invasion, and promoted apoptosis in vitro. However, due to the lack of a suitable cell tool, these results were not validated in vivo. In the present study, a thyroid cancer cell line with stable expression of CCDC67 and luciferase reporter genes was generated and identified. Firstly, cDNA clones of the CCDC67 gene were obtained by reverse transcription using a custom-designed primer. The results of subsequent electrophoresis analysis and sequencing revealed that the cDNA clones of CCDC67 gene were obtained successfully, with a length of $1,862 \mathrm{bp}$. The lentiviral vectors, containing the CCDC67, luciferase reporter and puromycin acetyltransferase genes, were co-transfected with two plasmids that encode lentiviral structural proteins and envelope proteins into 293T cells. Following ultracentrifugation, the titer of lentivirus was determined by ELISA to be $5.0 \times 10^{8} \mathrm{TU} / \mathrm{ml}$. The constructed lentiviral vector was used to transfect TPC-1 thyroid cancer cells, and stabilization was achieved by puromycin screening. The expression of CCDC67 gene, luciferase activity and tumorigenic ability of the generated cell line were detected. Reverse transcription-qPCR results demonstrated that the expression levels of CCDC67 gene in TPC-1 cells following transfection were increased 194,46.782-fold compared with those in the negative control group $(\mathrm{P}<0.01)$. A higher fluorescence intensity was detected in the generated cell line, while no detectable fluorescence was observed in untransfected TPC- 1 cells. The tumorigenic
\end{abstract}

Correspondence to: Professor Detao Yin, Department of Thyroid Surgery, The First Affiliated Hospital of Zhengzhou University, 1 Jianshe Road, Zhengzhou, Henan 450052, P.R. China

E-mail: detaoyin@zzu.edu.cn

Key words: thyroid cancer, coiled-coil domain containing 67, luciferase reporter gene, puromycin, TPC-1 ability of TPC-1-Luc-Puromycin-CCDC67 cells was verified by bioluminescence imaging and histopathological analysis using a pulmonary metastasis model. These results demonstrated that a thyroid cancer cell line with stable expression of CCDC67 and luciferase reporter genes was generated successfully. The TPC-1-Luc-Puromycin-CCDC67 cell line may be a helpful tool for further research on CCDC67 in vivo.

\section{Introduction}

Cancer of the thyroid gland is the most common endocrine malignancy, comprising $\sim 1 \%$ of all cancer cases in the United States of America (1,2). According to the pathological type, thyroid cancers are divided into papillary, follicular, medullary and anaplastic thyroid cancer (3), the first two of which are typically indolent tumors with a 5-year survival rate of $>95 \%$ (4). However, the metastasis of thyroid cancer to lung or other tissue is often observed at an early stage in certain cases (5-7). Primary thyroid tumors are usually well differentiated, but highly aggressive and respond poorly to standard therapies, which usually results in a poor prognosis and overall survival rate (8). Therefore, it is important to find a molecular biomarker that can predict and inhibit the malignant biological behavior of tumors.

Coiled-coil domain containing 67 (CCDC67) is a tumor suppressor gene that exhibits significant inhibitory effects on gastric, prostate and hepatocellular cancer (9-11). Our previous study demonstrated that the upregulation of CCDC67 gene has a significant inhibitory effect on thyroid cancer in vitro, which promotes the apoptosis of thyroid cancer cells and inhibits their proliferation, invasion and migration (12). However, due to the lack of a suitable cell tool, particularly cells with a fluorescent label that can be detected in living animals, these results were not tested in vivo.

Luciferase reporter gene, one of the most common gene reporter systems in animal experiments, achieves real-time monitoring of micrometastasis in non-invasive conditions (13). Luciferase is safe and sensitive, and exhibits high specificity and signal-to-noise ratio. Therefore, it can be used as a molecular label to observe the proliferation and metastasis of tumor cells indirectly through in vivo imaging systems (IVIS) (14).

In order to generate a reliable and convenient cell tool for further research on CCDC67 in vivo, a thyroid cancer 
cell line expressing CCDC67, luciferase and puromycin acetyltransferase (PAC) genes was generated. In addition, the tumorigenic ability of the generated cell line TPC-1-Luc-Puromycin-CCDC67 was validated in vivo. The newly generated cell line may provide a useful tracer cell for future studies.

\section{Materials and methods}

Cell lines and cell culture. The human papillary thyroid cancer cell line (TPC-1) and human embryonic kidney cell line (293T) were kindly provided by Dr Ye Lei of Shanghai Rui Jin Hospital (Shanghai, China). TPC-1 cells were cultured in RPMI-1640 (Beijing Solarbio Science \& Technology Co., Ltd.) medium supplemented with 10\% FBS (Gemini Bio Products), and 293T cells were cultured in DMEM (Beijing Solarbio Science \& Technology Co., Ltd.) supplemented with 10\% FBS. All cells were cultured in an atmosphere containing $5 \% \mathrm{CO}_{2}$ at $37^{\circ} \mathrm{C}$ and digested by $0.25 \%$ trypsin with $0.01 \%$ EDTA.

Construction and identification of a positive recombinant plasmid of CCDC67. To construct the lentiviral vector carrying the target gene, a positive recombinant plasmid was first constructed. The primer of the CCDC67 gene was designed and synthesized by Shanghai GeneChem Co., Ltd. Primer sequences were as follows: CCDC67 forward, 5'-GAGGAT CCCCGGGTACCGGTCGCCACCATGGAGAACCAAGCC CATAATAC-3' and reverse, 5'-TCACCATGGTGGCGACCG GTATGTGTCTATTTTGTTTTAGC-3'. The reverse transcription procedure was performed using a PrimeScript ${ }^{\mathrm{TM}}$ II kit (Takara Bio, Inc.) according to the manufacturer's protocol, and the cDNA fragment following amplification was cloned into a modified pCV146-Luc-Puromycin vector (Shanghai GeneChem Co., Ltd.). pCV146-Luc-Puromycin was linearized by BamHI/AgeI (Shanghai GeneChem Co., Ltd.) prior to mixing with purified cDNA fragment in a 1:5 ratio. T4 DNA ligase (Shanghai GeneChem Co., Ltd.) was used for the ligation reaction, and the ligation reaction system was as follows: $1 \mu \mathrm{l}$ linearized pCV146 vector $(100 \mathrm{ng} / \mu \mathrm{l})$, $1 \mu 1$ double-stranded DNA oligo, $2 \mu \mathrm{l}$ 10X T4 DNA ligase

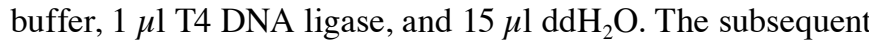
conversion reaction and sequencing of positive clones were performed by Majorbio Technology Co., Ltd. Sequencing results were analyzed and compared with the sequence of CCDC67 gene in GenBank (https://www.ncbi.nlm.nih.gov/ nuccore/KJ906442.1?report=fasta) using Chromas software (version 2.0; Miaolingbio) The positive recombinant plasmid was termed pCV146-Luc-Puromycin-CCDC67.

Packaging and concentration of lentiviral vectors. $293 \mathrm{~T}$ cells were seeded in a $15-\mathrm{cm}$ culture dish at a density of $6 \times 10^{6} \mathrm{cells} / \mathrm{ml}$, and the serum-free DMEM was replaced when the cell density reached $\sim 80 \%$. Transfection complex solution comprised $20 \mu \mathrm{g}$ pCV146-Luc-Puromycin-CCDC67 vectors, $15 \mu \mathrm{g}$ pHelper 1.0 vectors (Shanghai GeneChem Co., Ltd.), $10 \mu \mathrm{g}$ pHelper 2.0 vectors (Shanghai GeneChem Co., Ltd.), $100 \mu$ l Lipofectamine ${ }^{\circledR} 2000$ (Shanghai GeneChem Co., Ltd.) and $4.9 \mathrm{ml}$ Opti-MEM medium (Shanghai GeneChem Co., Ltd.). Following configuration according to the manufacturer's protocol, the transfection complex solution was added to the culture dish with $293 \mathrm{~T}$ cells. At $8 \mathrm{~h}$, the culture medium was replaced with DMEM containing 10\% FBS. The supernatant of 293T cells was collected at $48 \mathrm{~h}$, and the lentivirus was concentrated by ultracentrifugation $\left(4.472 \times 10^{4} \mathrm{x}\right.$ g at $4^{\circ} \mathrm{C}$ for $3 h)$.

Determination of the lentivirus titer. HIV-1 p24 Antigen ELISA 2.0 kit (ZeptoMetrix Corporation) was used to determine the titer of the lentivirus. HIV-1 p24 Antigen Standard was diluted to $125.0,62.5,31.3,15.6,7.8$ and $3.9 \mathrm{pg} / \mathrm{ml}$ in PBS. The lentivirus solution was diluted with PBS and the dilution ratios of $1: 1 \times 10^{6}$ and $1: 1 \times 10^{7}$ were selected for testing. A total of $200 \mu \mathrm{l}$ Antigen Standard in different concentrations and diluted lentivirus samples were added into a microwell plate separately. Subsequently, the plate was sealed by Parafilm ${ }^{\circledR}$ and placed in an oven at $37^{\circ} \mathrm{C}$ for $1.5 \mathrm{~h}$. The samples were removed and $100 \mu 1 \mathrm{HIV}-1 \mathrm{p} 24$ Detector Antibody was added to each well, with the exception of the control wells. The plate was maintained at room temperature for $30 \mathrm{~min}$ in the dark. After the sample wells with p24 turned blue, $100 \mu 1$ Stop Solution was added to stop the reaction. Optical density at $450 \mathrm{~nm}$ was detected within 15 min by an automatic enzyme-linked immunosorbent assay plate reader (Bio-Rad Laboratories, Inc.).

Cell transfection and screening. TPC-1 cells were seeded at $2 \times 10^{5}$ cells/well in 6 -well plates. After the cells attached to the wall, $10 \mu 1$ lentivirus with a titer of $2 \times 10^{8} \mathrm{TU} / \mathrm{ml}$ (MOI=10) and $40 \mu \mathrm{l}$ HitransG P infection enhancer (Shanghai GeneChem Co., Ltd.) were added into each well. At $8 \mathrm{~h}$, the culture medium was replaced with RPMI-1640 medium containing $10 \%$ FBS. The cells were screened by culture medium containing $2.5 \mu \mathrm{g} / \mathrm{ml}$ puromycin (PerkinElmer, Inc.). After $48 \mathrm{~h}$, culture medium containing $1.5 \mu \mathrm{g} / \mathrm{ml}$ puromycin was used to screen for $\geq 2$ weeks to obtain a stable transfected cell line. The generated thyroid cancer cell line was termed TPC-1-Luc-Puromycin-CCDC67. An empty lentiviral vector was used for negative control.

Reverse transcription-quantitative polymerase chain reaction (RT-qPCR). The expression of CCDC67 gene was detected by RT-qPCR. The primers of CCDC67 and GAPDH genes were synthesized by Shanghai GeneChem Co., Ltd., and the sequences were as follows: CCDC67 forward, 5'-GAGGATC CCCGGGTACCGGTCGCCACCATGGAGAACCAAGCCC ATAATAC-3' and reverse, 5'-TCACCATGGTGGCGACCG GTATGTGTCTATTTTGTTTTAGC-3'; GAPDH forward, 5'-TGAAGGTCGGAGTCAACGG-3' and reverse, 5'-CTGGAA GATGGTGATGGGATT-3'. Total RNA was extracted from TPC-1 and TPC-1-Luc-Puromycin-CCDC67 cells (continuously cultured in puromycin-free medium for $\geq 4$ weeks) using TRIzol $^{\circledR}$ reagent (Invitrogen; Thermo Fisher Scientific, Inc.), and $1 \mu \mathrm{l}$ total RNA was reverse-transcribed to cDNA using PrimeScript $^{\mathrm{TM}}$ II kit (Takara Bio, Inc.) according to the manufacturer's protocol. The resulting cDNA was quantified using a RT-qPCR mRNA SYBR Green Detection kit (Takara Bio, Inc.). The resulting cDNA $(2 \mu \mathrm{l})$ was used as the template for PCR in a 20- $\mu \mathrm{l}$ reaction volume containing $10 \mu \mathrm{l} 2 \mathrm{X}$ SYBR Premix Ex Taq II, $0.8 \mu \mathrm{l}$ each of $10 \mu \mathrm{mol} / \mathrm{l}$ forward and reverse

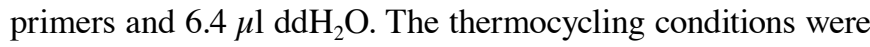
as follows: $5 \mathrm{sec}$ at $95^{\circ} \mathrm{C}$, followed by 50 cycles of $95^{\circ} \mathrm{C}$ for $5 \mathrm{sec}$, 

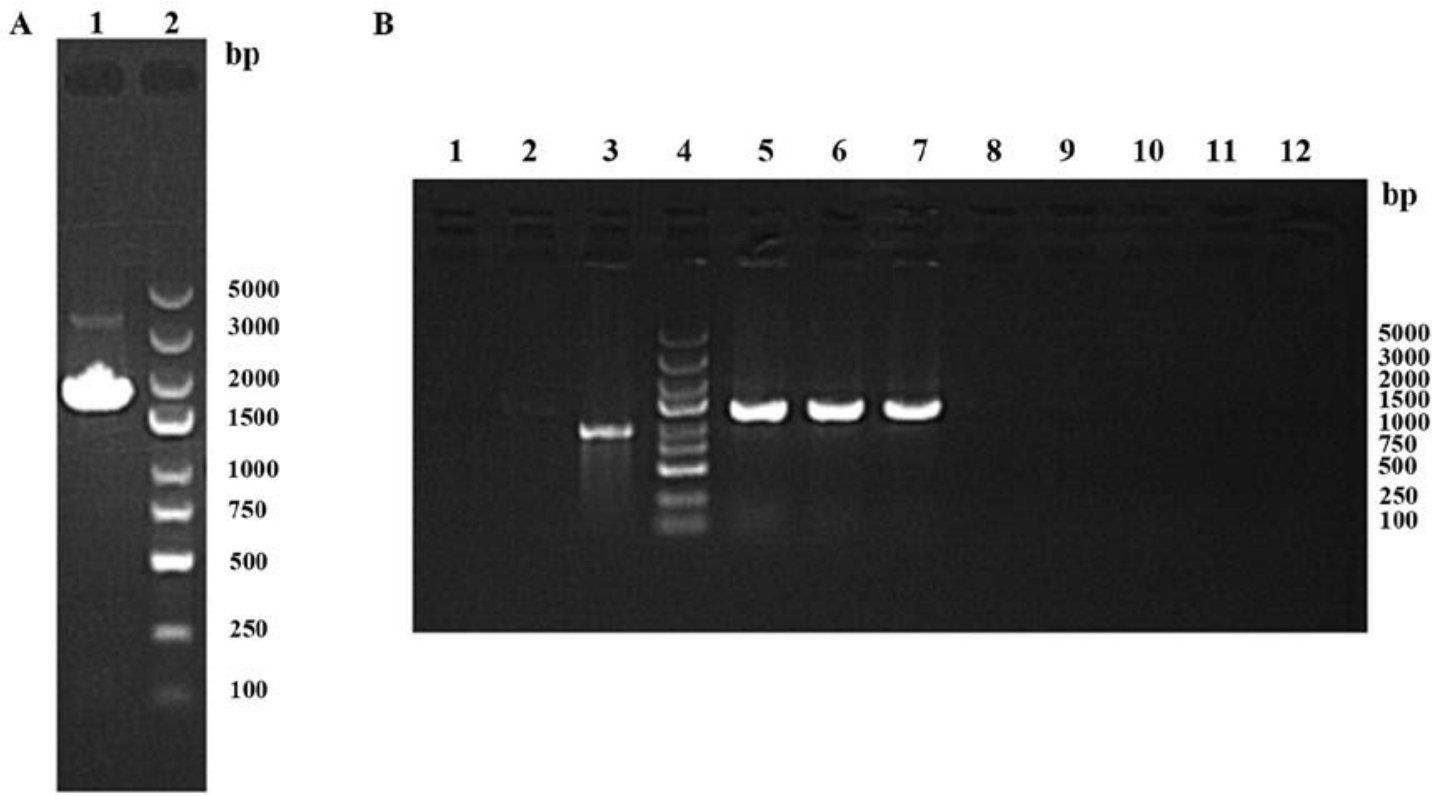

Figure 1. PCR amplification of CCDC67. (A) Results of PCR amplification of the CCDC67 gene. 1, CCDC67; 2, marker. (B) Results of PCR amplification of the positive clones. 1, $\mathrm{ddH}_{2} \mathrm{O}$ (negative control); 2, empty vector (negative control); 3, GAPDH (positive control); 4, marker; 5-12: positive clones. CCDC67, coiled-coil domain-containing 67.

$60^{\circ} \mathrm{C}$ for $50 \mathrm{sec}$. The mRNA expression level of GAPDH was used for normalization. The threshold cycle $(\mathrm{Cq})$ value was recorded, and the data were analyzed by the comparative $2^{-\Delta \Delta \mathrm{Cq}}$ method (15).

Luciferase activity assay in vitro. TPC-1 and TPC-1-LucPuromycin-CCDC67 cells (continuously cultured in puromycin-free medium for $\geq 4$ weeks) were diluted to $5.0 \times 10^{5}$, $2.5 \times 10^{5}, 1.3 \times 10^{5}, 0.6 \times 10^{5}$ and $0.3 \times 10^{5}$ cells $/ \mathrm{ml}$ and inoculated into a 24-well plate. This was done to demonstrate that the fluorescence intensity increased with increasing cell number. After the cells attached to the wall, D-luciferin (PerkinElmer, Inc.) was added to a final concentration of $100 \mathrm{mg} / \mathrm{ml}$. At $3 \mathrm{~min}$, fluorescence intensity was measured using IVIS.

Tumorigenesis assay in vivo. A total of 5 female SCID Beige mice (4-5 weeks old; initial body weight: 15-18 g) were used to establish an animal model of pulmonary metastasis (16). The mice were maintained in specific pathogen-free housing at Henan Key Laboratory for Pharmacology of Liver Diseases (temperature, $27^{\circ} \mathrm{C}$; humidity: $50 \%$; light cycle, $10 \mathrm{~h}$ light, $14 \mathrm{~h}$ darkness; food and water, ad libitum). A preliminary experiment revealed that a total of $200 \mu \mathrm{l}$ TPC-1-Luc-Puromycin-CCDC67 cells $\left(1 \times 10^{7}\right.$ cells $\left./ \mathrm{ml}\right)$ achieved a higher tumor formation rate and a longer cell survival time. Cells were administered to SCID Beige mice by tail vein injection. At 2, 3 and 4 weeks after injection, mice $(n=5)$ were intraperitoneally injected with $200 \mu \mathrm{l}$ D-luciferin solution $(150 \mathrm{mg} / \mathrm{kg}$ body weight; PerkinElmer, Inc.) and anesthetized with $2 \%$ isoflurane. After $10 \mathrm{~min}$, the mice were placed into IVIS for bioluminescence imaging. Body weights were recorded daily. Considering requirements of experimental animal ethics, mice were sacrificed by cervical dislocation after $\mathrm{CO}_{2}$ euthanasia (flow rate of $\mathrm{CO}_{2}: 5 \mathrm{l} / \mathrm{min}$; size of chamber: $40 \times 30 \times 25 \mathrm{~cm}$ ) when the mice lost $>2 \mathrm{~g}$ body weight (17). Lungs and other organs containing metastatic foci were excised for ex vivo bioluminescence imaging. A control experiment was not performed as the main purpose of the tumorigenesis assay was to examine the tumorigenic ability of the generated cell line.

Histopathological assay. Lungs and other organs in which metastatic foci were detected were fixed in $4 \%$ paraformaldehyde at room temperature for $24 \mathrm{~h}$, embedded in paraffin and cut into $4-\mu \mathrm{m}$ sections. Following staining with hematoxylin for $3 \mathrm{~min}$ and eosin for $2 \mathrm{~min}$ at room temperature, the sections were observed and imaged using an upright fluorescence microscope (cat. no. TS100-F; magnification, $\mathrm{x} 40$ or $\mathrm{x} 200$; Nikon Corporation) with a digital image capturing system using NIS-Elements D software (version 2.30; Nikon Corporation).

Statistical analysis. The results of at least three independent experiments are presented as mean \pm standard deviation. Simple linear regression was used to detect the titer of lentivirus. Student's t-test was performed to evaluate the differences in the expression levels of CCDC67 gene. Comparison between multiple groups was performed using one-way analysis of variance followed by the Student-Newman-Keuls post hoc test. $\mathrm{P}<0.05$ was considered to indicate a statistically significant difference. Statistical analyses were performed using SPSS 21.0 software for Windows (IBM Corp.). GraphPad Prism 5 (GraphPad Software, Inc.) was used to plot the data.

\section{Results}

Construction and identification of a positive recombinant plasmid of CCDC67. The full length of CCDC67 gene was selected as the template for PCR amplification. The PCR products were tested by agarose gel electrophoresis. The results demonstrated that a specific bright band was amplified at 


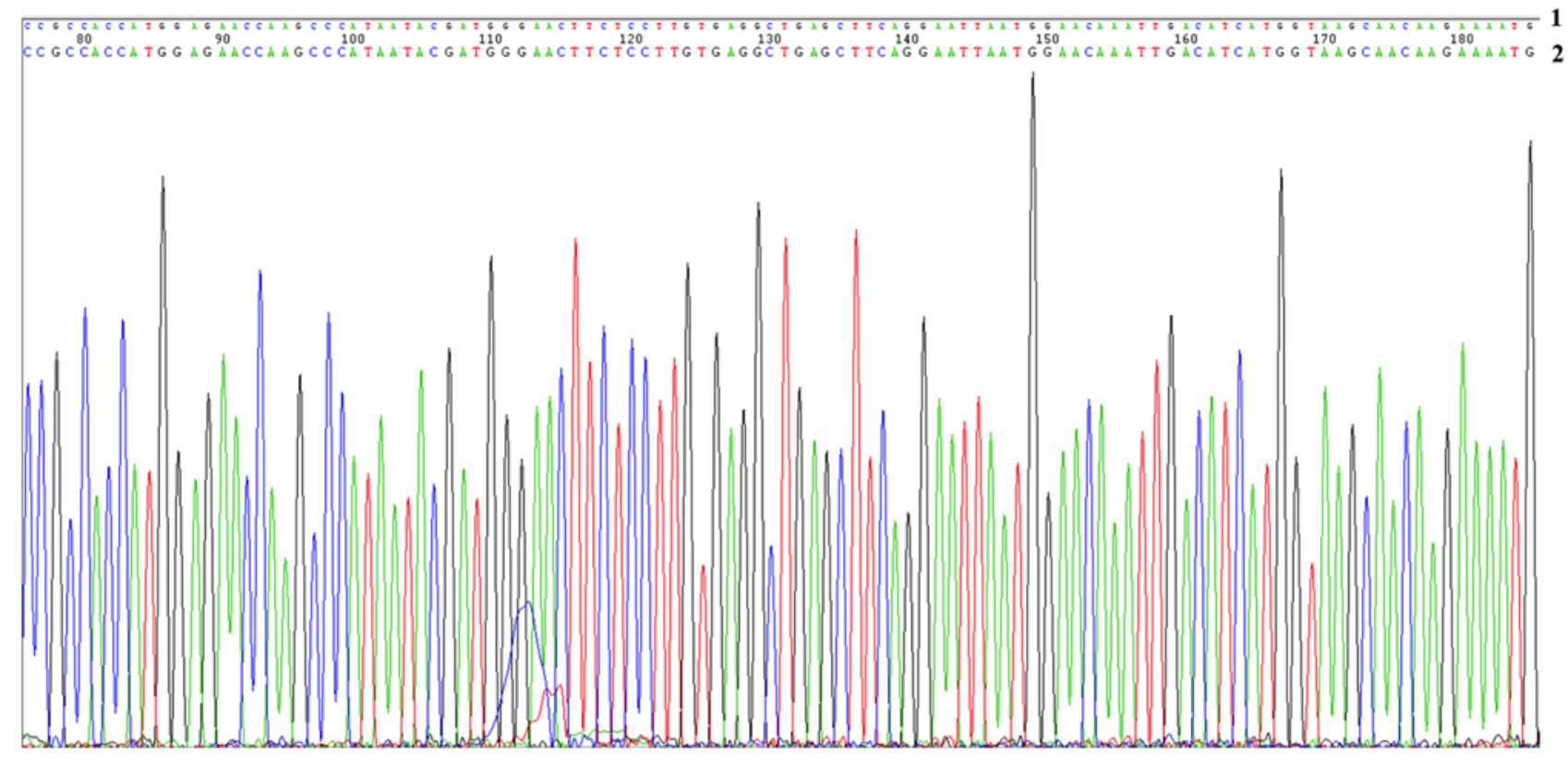

Figure 2. Sequencing results (80-180 bp) of the recombinant positive clones. 1, the original sequence of CCDC67 gene in GenBank NM-181645; 2 , sequencing results of the chosen positive clone. CCDC67, coiled-coil domain-containing 67.

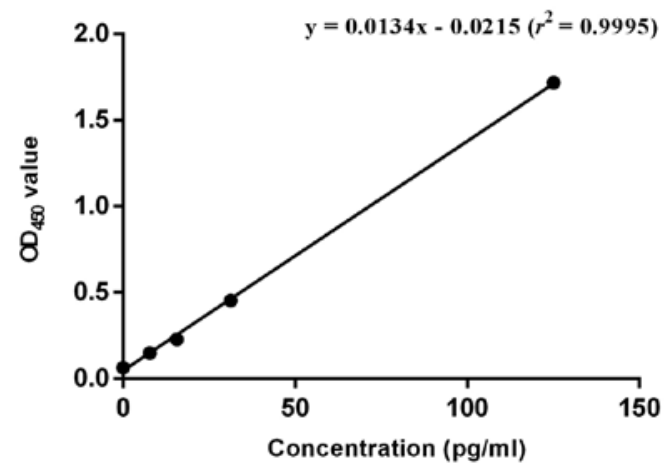

Figure 3. Standard curve of ELISA essay. The five dots along the line represent HIV-1 p24 Antigen Standard in five different concentrations and the corresponding $\mathrm{OD}_{450}$ values. A linear equation was obtained by linear regression analysis. $\mathrm{OD}_{450}$, optical density at $450 \mathrm{~nm}$.

1,862 bp (Fig. 1A). The purified CCDC67 gene was digested, ligated and transformed with the vector pCV146-luc-puromycin. A total of eight positive clones were selected to be mixed with Escherichia coli, and the identification results of the bacterial liquid revealed that a specific bright band was amplified at 1,392 bp in three of the eight positive clones (Fig. 1B). The sequencing results of the three positive clones were compared with the original sequence of CCDC67 gene in GenBank (NM-181645), and only one of them fully matched the sequence in GenBank NM-181645 (Fig. 2). The positive recombinant plasmid pCV146-luc-puromycin-CCDC67 was constructed by introducing the selected positive clone to the vector pCV146-luc-puromycin.

Determination of the virus titer. A standard curve was drawn using the corresponding $\mathrm{OD}_{450}$ values of different concentrations of HIV-1 p24 Antigen Standard (Fig. 3). The linear equation of the obtained standard curve was:

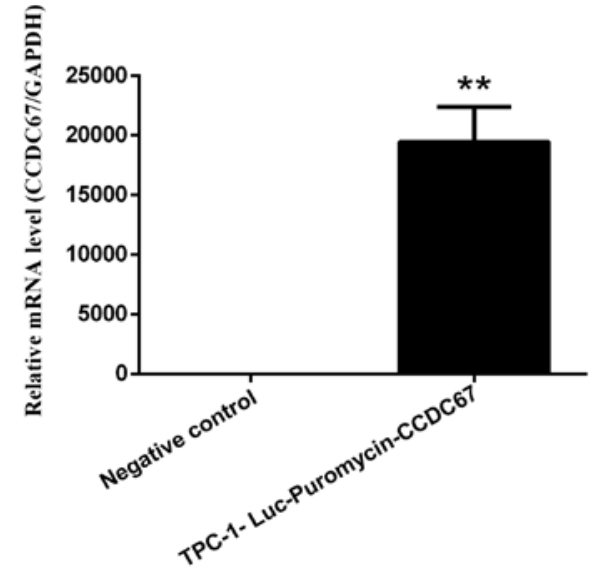

Figure 4. Relative mRNA level of CCDC67 gene. ${ }^{* *} \mathrm{P}<0.01$ vs. negative control. Negative control, TPC-1 cells transfected with empty CV146-Luc-Puromycin vectors; CCDC67, coiled-coil domain-containing 67.

$\mathrm{y}=0.0134 \mathrm{x}-0.0215\left(\mathrm{r}^{2}=0.9995\right)$. Based on the $\mathrm{OD}_{450}$ values of the two samples (dilution ratios of $1: 1 \times 10^{6}$ and $1: 1 \times 10^{7}$ ), the average concentration of the original lentivirus solution was $5.0 \times 10^{7} \mathrm{pg} / \mathrm{ml}$ (Table I). According to the conversion relation between concentration and titer of virus provided by ELISA kit $(10 \mathrm{TU}=1 \mathrm{pg})$, the titer of original lentivirus was $5.0 \times 10^{8} \mathrm{TU} / \mathrm{ml}$.

Detection of the relative $m R N A$ level of CCDC67 gene. TPC-1 cells transfected with empty vectors (negative control group) and TPC-1-Luc-Puromycin-CCDC67 cells were screened with puromycin and continuously cultured in puromycin-free medium for $\geq 4$ weeks. The relative mRNA expression level of CCDC67 in the two groups was assessed by RT-qPCR. The results demonstrated that the expression level of CCDC67 gene in TPC-1-Luc-Puromycin-CCDC67 cells was 19,446.782-fold higher compared with that in the negative control group $(\mathrm{P}<0.01$; Fig. 4). 
Table I. The $\mathrm{OD}_{450}$ value of virus solution in two dilution ratios.

\begin{tabular}{lccccc}
\hline Sample & Dilution ratio & $\mathrm{OD}_{450}$ & Concentration, $\mathrm{pg} / \mathrm{ml}$ & Raw virus solution, $\mathrm{pg} / \mathrm{ml}$ & Average, $\mathrm{pg} / \mathrm{ml}$ \\
\hline 1 & $1 \times 10^{6}$ & 0.413 & 32.4 & $3.2 \times 10^{7}$ & $5.0 \times 10^{7}$ \\
2 & $1 \times 10^{7}$ & 0.071 & 6.9 & $6.9 \times 10^{7}$ & \\
\hline
\end{tabular}

$\mathrm{OD}_{450}$, optical density at $450 \mathrm{~nm}$.

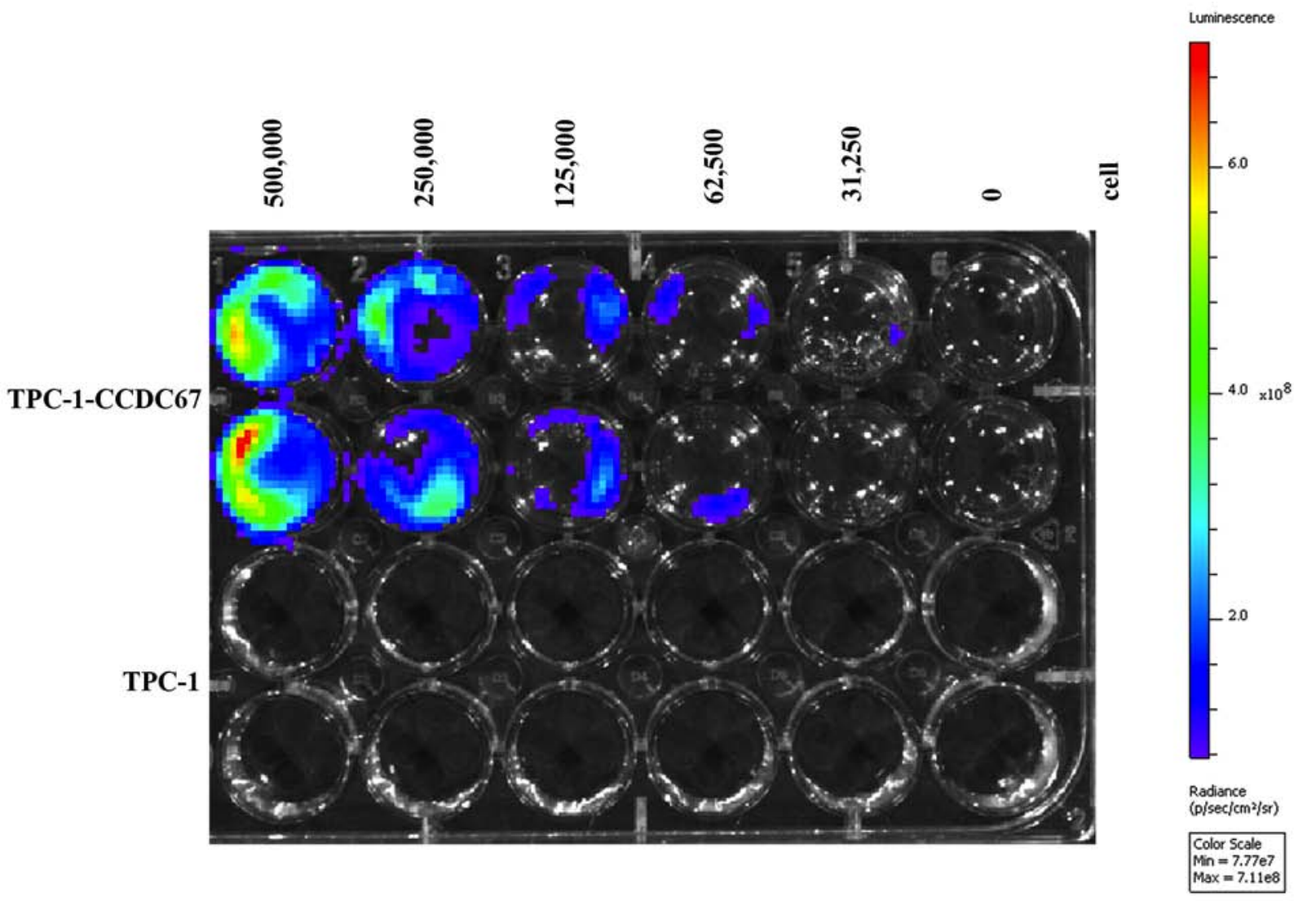

Figure 5. Luciferase activity assay. The assay detected high luciferase activity in TPC-1-Luc-Puromycin-CCDC67 cells, whereas no fluorescence was detected in untransfected TPC-1 cells. In addition, the fluorescence intensity increased with the number of cells. TPC-1-CCDC67, TPC-1-Luc-Puromycin-CCDC67 cells; TPC-1, untransfected TPC-1 cells; CCDC67, coiled-coil domain-containing 67.

Detection of luciferase activity. All cells used for luciferase activity assay were screened with puromycin and continuously cultured in puromycin-free medium for $\geq 4$ weeks. The results of the luciferase activity assay demonstrated that high luciferase activity was detected in TPC-1-Luc-Puromycin-CCDC67 cells, whereas no fluorescence was detected in untransfected TPC-1 cells (Fig. 5). In addition, the fluorescence intensity increased with the number of cells (Fig. 5).

Identification of tumorigenic ability in vivo. The tumorigenic ability of generated cell line were verified using an animal model of pulmonary metastasis. The growth of tumors was monitored by bioluminescence imaging (Fig. 6A). At week 2, fluorescent foci were only detected in the lungs of one mouse. At week 3, fluorescent foci in one or both lungs were detected in all mice, resulting in a tumor formation rate of $100 \%(5 / 5)$.
Quantification analysis of bioluminescence intensity demonstrated time-dependent tumor growth (Fig. 6B). In addition, the body weight of the mice exhibited a slight drop in the duration of tumor bearing (Fig. 6C), which suggested that the involvement of thyroid tumors affected the normal growth of mice.

Bioluminescence imaging and histopathological analysis. At week 4, both lungs and other tissues with fluorescent foci were resected for ex vivo bioluminescence imaging to confirm the metastasis of tumors. Fluorescent foci were detected in one or both lungs of all mice (Fig. 7), suggesting the lung metastasis of tumor cells. Subsequent histopathological analysis further confirmed this result (Fig. 8). In mice 2, 4 and 5, a small number of tumor cells escaped during tail vein injection, resulting in strong fluorescence foci in the lower abdomen. In order to eliminate interference from unrelated fluorescent foci, 

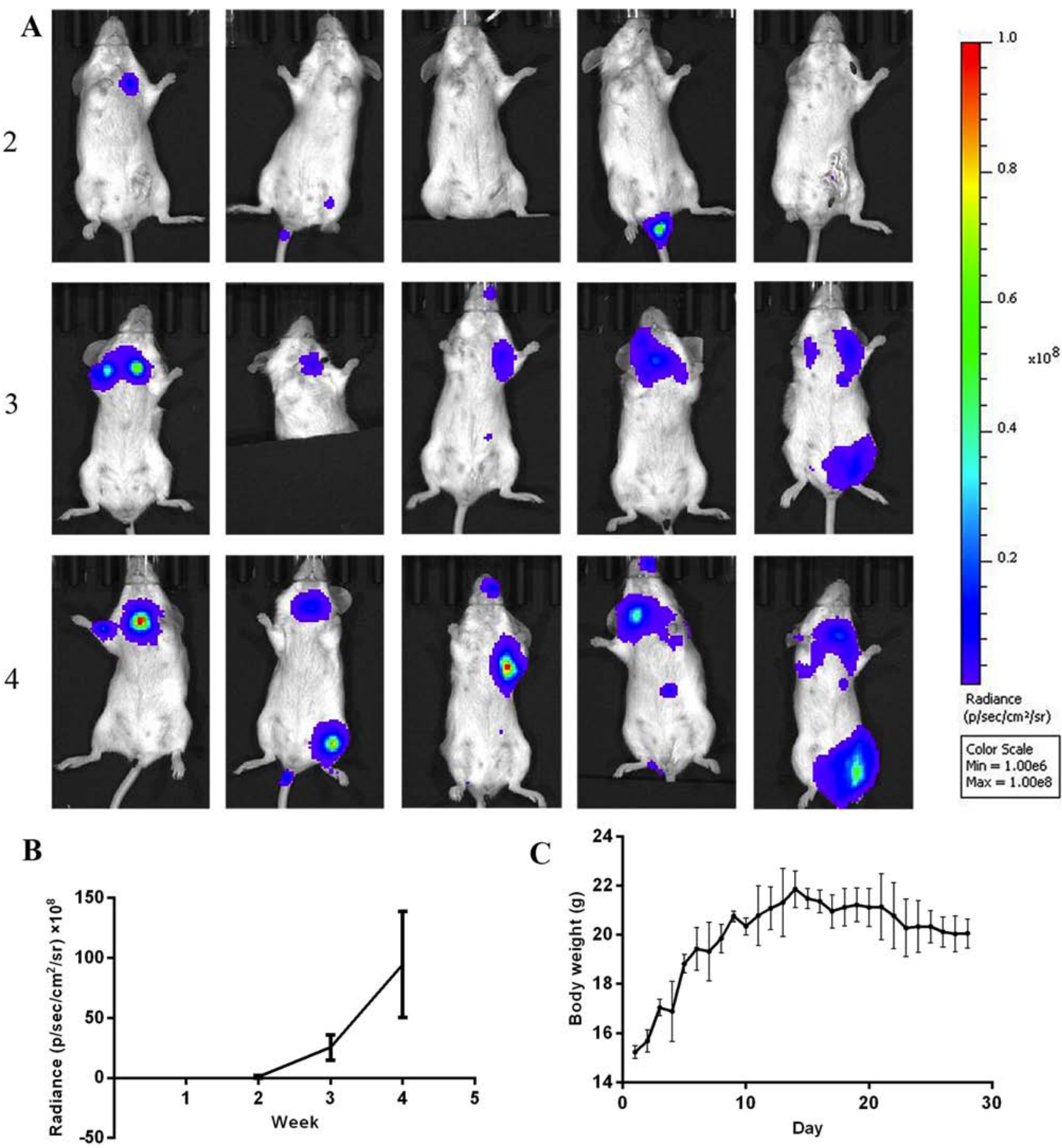

Figure 6. In vivo bioluminescence imaging of tumor growth. (A) At week 2, 3 and 4 after injection, mice $(n=5)$ were imaged to observe the growth of tumors. (B) The quantification analysis of bioluminescence intensity demonstrated time-dependent growth of tumors. (C) Body weight observation.

opaque black paper was used to cover these areas. In addition, a fluorescent focus was also detected in the submandibular gland tissue of a mouse, and pathological results confirmed tumor metastasis.

\section{Discussion}

Clinical studies have demonstrated that thyroid cancer is a malignant tumor with a 5-year survival rate of $>89 \%$; however, if metastasis occurs, the survival rate of patients is reduced to $51 \%$ (18). Therefore, early diagnosis and prognostic assessment of thyroid cancer are of great significance.
However, an accurate early diagnosis and a complete prognostic assessment are relatively difficult due to the inconspicuous clinical symptoms and limitation of fine needle aspiration biopsy, including the the size and location of nodules and the unavailability of an experienced thyroid surgeon in grassroots hospitals in China. Molecular markers are effectively applied in this area, especially in thyroid nodules with cytological uncertainty $(19,20)$. The classical oncogenic genetic alterations commonly observed in thyroid cancer include BRAF V600E, TERT promoter and Ras mutation, RET/PTC rearrangements and PAX8-peroxisome proliferator-activated receptor $\gamma$ fusion oncogene (21-24), 

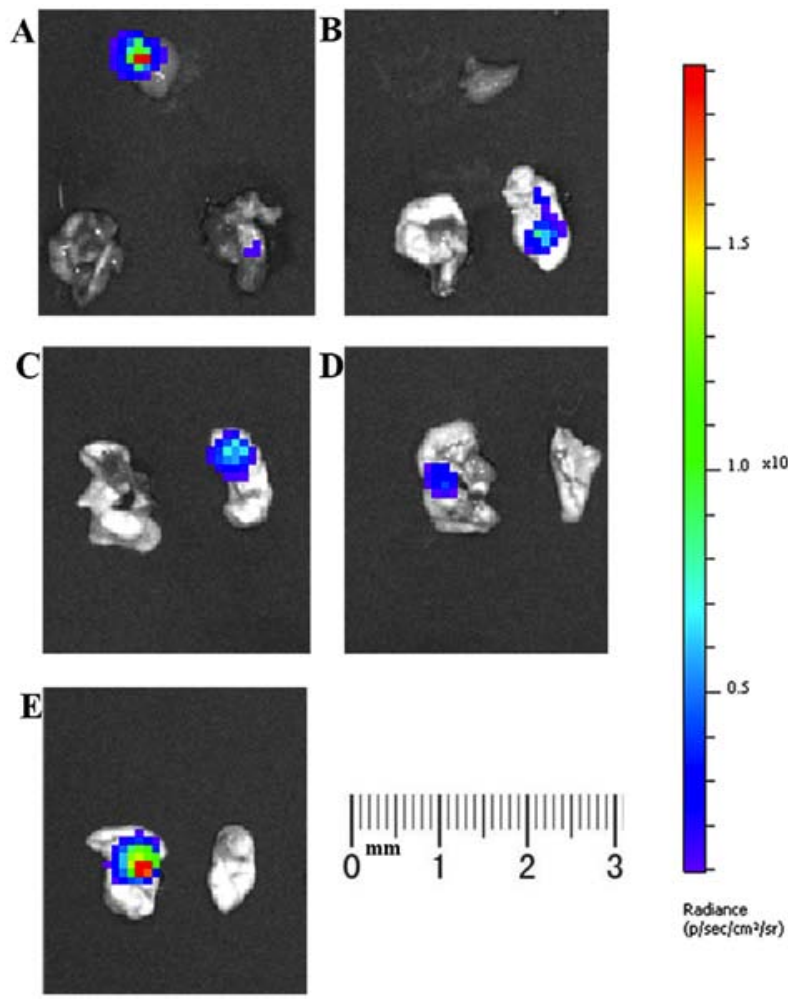

Figure 7. Ex vivo bioluminescence imaging of the dissected tissue. (A) Lung tissues and the submandibular gland of mouse 1. (B) Lung tissues and the submandibular gland of mouse 2. (C) Lung tissues of mouse 3. (D) Lung tissues of mouse 4. (E) Lung tissues of mouse 5 (tissue on the top, submandibular gland; tissue on the left, right lung; tissue on the right, left lung). Fluorescent foci were detected in at least one side of lung tissues in all mice. Besides, in mice 1 and 2, fluorescent foci are detected in the submandibular gland region, suggesting that tumor may metastasize to the submandibular gland, but it is only validated in A.
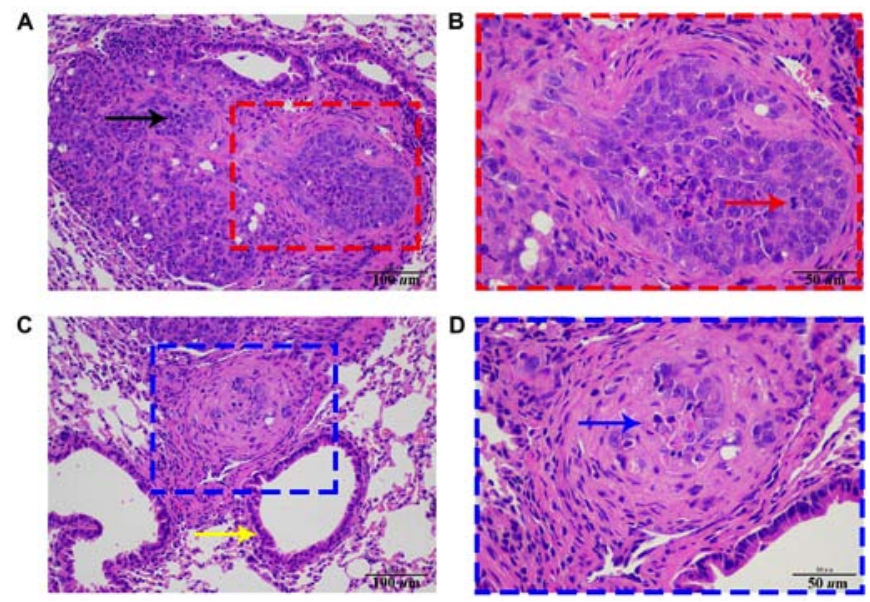

Figure 8. Hematoxylin and eosin staining of the dissected tissue (A) Metastatic tumor foci were observed in resected lung tissue (black arrow). Magnification, x200. (B) Several mitotic tumor cells were found in tumor tissue, suggesting that cell proliferation was active (red arrow) Magnification, $x$ 400. (C) A small amount of lymphocyte infiltration was seen around the metastatic focus (yellow arrow). Magnification, x200. (D) A mass of tumor cells was surrounded by connective tissue around the bronchi (blue arrow). Magnification, x400.

each of which has benefits and limitations for the early diagnosis and prognostic assessment. Therefore, combined genetic detection may be applied to obtain a more accurate and complete assessment for individualized treatment of tumors (25). New generation technology in gene detection has enabled the simultaneous detection of multiple genes (26), but the application of gene detection in the diagnosis and treatment of thyroid cancer remains limited, since our understanding about the pathogenesis of thyroid cancer is still insufficient and the molecular markers are limited. Therefore, it is necessary to continuously explore the complex molecular pathways and pathogenesis-related processes of thyroid cancer.

CCDC67 gene is a tumor-suppressor gene in papillary thyroid cancer, and our previous in vitro study has demonstrated that CCDC67 is a reliable molecular marker with potential to predict the malignant biological properties of thyroid cancers (12). However, these results were not validated in the complex physiological environment in vivo. A stable and controllable animal model is an essential factor in in vivo experiments, and the construction of an animal model is based on a mature and reliable cell tool. In order to generate a suitable cell line for further in vivo research, not only a successful intervention (silencing or overexpression) of the target gene needs to be achieved, but also an applicable fluorescent marker and antibiotic resistance gene are required, which may facilitate the dynamic monitoring of tumor cell growth. Classical fluorescent markers, such as green, red and blue fluorescent protein, are stable, hypotoxic and easily visualized, but for in vivo experiments (27-29), the luciferase reporting system is preferable, as it is non-toxic, sensitive and exhibits a high signal-to-noise ratio (30). In addition, numerous antibiotic resistance genes exist for screening, and PAC is one of the common types used in lentiviral vectors, which may be related to certain biological characteristics of lentiviral vectors. In the present study, a thyroid cancer cell line expressing CCDC67 gene, luciferase reporter gene and puromycin acetyltransferase gene simultaneously was generated and identified.

The construction of the cell line TPC-1-Luc-PuromycinCCDC67 may provide a convenient tool for the establishment of a lung metastasis and orthotopic models of thyroid cancer, which enables further evaluation of the tumor inhibition effect and mechanism of CCDC67 in vivo. The lentiviral vector constructed in the present study has the potential to be a useful tool for transforming other tumor cell lines.

\section{Acknowledgements}

The authors would like to thank Dr Peng Youmei (Henan Key Laboratory for Pharmacology of Liver Diseases) for guidance on animal experiments and Dr Wang Ning (Henan Key Laboratory for Pharmacology of Liver Diseases) for assisting with in vivo imaging.

\section{Funding}

The present study was supported by a grant from the National Natural Science Foundation of China (grant no. 81372863), College Scientific and Technological Innovation Team Project of Henan Province (grant no. 19IRTSTHN002) and Thousand Talents Program of Central China (grant no.ZYQR201810015). 


\section{Availability of data and materials}

The datasets used and analyzed during the present study are available from the corresponding author on reasonable request.

\section{Authors' contributions}

LZ and DY conceived and designed the experiments. LZ, FY, $\mathrm{CL}$ and RM performed the experiments. ML and LW collected and analyzed the data. RM and ML provided suggestions and technical support on the project. DY wrote the manuscript and supervised the project. All authors read and approved the final manuscript.

\section{Ethics approval and consent to participate}

The animal experiments in this study were approved by the Ethical Committee of Zhengzhou University (Zhengzhou, China).

\section{Patient consent for publication}

Not applicable.

\section{Competing interests}

The authors declare that they have no competing interests.

\section{References}

1. Yu Y, Yu X, Fan C, Wang H, Wang R, Feng C and Guan $\mathrm{H}$ : Targeting glutaminase-mediated glutamine dependence in papillary thyroid cancer. J Mol Med (Berl) 96: 777-790, 2018.

2. Hardin H, Helein H, Meyer K, Robertson S, Zhang R, Zhong W and Lloyd RV: Thyroid cancer stem-like cell exosomes: Regulation of EMT via transfer of lncRNAs. Lab Invest 98: 1133-1142, 2018.

3. Raue F and Frank-Raue K: Thyroid cancer: Risk-stratified management and individualized therapy. Clin Cancer Res 22 5012-5021, 2016

4. Nikitski AV, Rominski SL, Wankhede M, Kelly LM, Panebianco F, Barila G, Altschuler DL and Nikiforov YE: Mouse model of poorly differentiated thyroid carcinoma driven by STRN-ALK fusion. Am J Pathol 188: 2653-2661, 2018.

5. Yang J, Li LF, Zhang XM, Xu Q, Zhang J, Weng WW and Dong MJ: Unusual synchronous skeletal muscle and lung metastasis in papillary thyroid cancer: A case report and review of the literature. Oncol Lett 9: 727-730, 2015.

6. Bruglia M, Palmonella G, Silvetti F, Rutigliano P, Criante P Marmorale C, Boscaro M and Taccaliti A: Skin and thigh muscle metastasis from papillary thyroid cancer. Singapore Med J 50: e61-e64, 2009.

7. Luo Q, Luo QY, Sheng SW, Chen LB, Yu YL, Lu HK and Zhu RS: Localization of concomitant metastases to kidney and erector spinae from papillary thyroid carcinoma using (131)I-SPECT and CT. Thyroid 18: 663-664, 2008

8. American Thyroid Association (ATA) Guidelines Taskforce on Thyroid Nodules and Differentiated Thyroid Cancer, Cooper DS Doherty GM, Haugen BR, Kloos RT, Lee SL, Mandel SJ, Mazzaferri EL, McIver B, Pacini F, et al: Revised American Thyroid Association management guidelines for patients with thyroid nodules and differentiated thyroid cancer. Thyroid 19: $1167-1214,2009$

9. Park SJ, Jang HR, Kim M, Kim JH, Kwon OH, Park JL, Noh SM, Song KS, Kim SY, Kim YH and Kim YS: Epigenetic alteration of CCDC67 and its tumor suppressor function in gastric cancer. Carcinogenesis 33: 1494-1501, 2012.

10. Yu YP, Ding Y, Chen Z, Liu S, Michalopoulos A, Chen R, Gulzar ZG, Yang B, Cieply KM, Luvison A, et al: Novel fusion transcripts associate with progressive prostate cancer. Am J Pathol 184: 2840-2849, 2014
11. Chen ZH, Yu YP, Zuo ZH, Nelson JB, Michalopoulos GK, Monga S, Liu S, Tseng G and Luo JH: Targeting genomic rearrangements in tumor cells through Cas9-mediated insertion of a suicide gene. Nat Biotechnol 35: 543-550, 2017.

12. Yin DT, Xu J, Lei M, Li H, Wang Y, Liu Z, Zhou Y and Xing M: Characterization of the novel tumor-suppressor gene CCDC67 in papillary thyroid carcinoma. Oncotarget 7: 5830-5841, 2016.

13. Sekiguchi Y, Owada J, Oishi H, Katsumata T, Ikeda K, Kudo T and Takahashi S: Noninvasive monitoring of $\beta$-cell mass and fetal $\beta$-cell genesis in mice using bioluminescence imaging. Exp Anim 61: 445-451, 2012.

14. Tu SH, Hsieh YC, Huang LC, Lin CY, Hsu KW, Hsieh WS, Chi WM and Lee $\mathrm{CH}$ : A rapid and quantitative method to detect human circulating tumor cells in a preclinical animal model. BMC Cancer 17: 440, 2017.

15. Feng L, Jia X, Zhu M, Chen Y and Shi F: Chemoprevention by Prunella vulgaris L. extract of non-small cell lung cancer via promoting apoptosis and regulating the cell cycle. Asian Pac J Cancer Prev 11: 1355-1358, 2010.

16. Kato H, Wakabayashi H, Naito $Y$, Kato $S$, Nakagawa $T$, Matsumine A and Sudo A: Anti-tumor necrosis factor therapy inhibits lung metastasis in an osteosarcoma cell line. Oncology 88: 139-146, 2015.

17. Boivin GP, Bottomley MA, Schiml PA, Goss L and Grobe N: Physiologic, behavioral, and histologic responses to various euthanasia methods in C57BL/6NTac male mice. J Am Assoc Lab Anim Sci 56: 69-78, 2017.

18. Randle RW, Balentine CJ, Leverson GE, Havlena JA, Sippel RS, Schneider DF and Pitt SC: Trends in the presentation, treatment, and survival of patients with medullary thyroid cancer over the past 30 years. Surgery 161: 137-146, 2017.

19. Pstrag N, Ziemnicka K, Bluyssen H and Wesoły J: Thyroid cancers of follicular origin in a genomic light: In-depth overview of common and unique molecular marker candidates. Mol Cancer 17: 116, 2018.

20. Bath SC, Pop VJ, Furmidge-Owen VL, Broeren MA and Rayman MP: Thyroglobulin as a functional biomarker of iodine status in a cohort study of pregnant women in the United Kingdom. Thyroid 27: 426-433, 2017.

21. Xing M: BRAF mutation in thyroid cancer. Endocr Relat Cancer 12: 245-262, 2005

22. Liu X, Bishop J, Shan Y, Pai S, Liu D, Murugan AK, Sun H, El-Naggar AK and Xing M: Highly prevalent TERT promoter mutations in aggressive thyroid cancers. Endocr Relat Cancer 20: 603-610, 2013.

23. Basolo F, Pisaturo F, Pollina LE, Fontanini G, Elisei R, Molinaro E, Iacconi P, Miccoli P and Pacini F: N-ras mutation in poorly differentiated thyroid carcinomas: Correlation with bone metastases and inverse correlation to thyroglobulin expression. Thyroid 10: 19-23, 2000.

24. Dwight T, Thoppe SR, Foukakis T, Lui WO, Wallin G, Höög A, Frisk T, Larsson C and Zedenius J: Involvement of the PAX8/peroxisome proliferator-activated receptor gamma rearrangement in follicular thyroid tumors. J Clin Endocrinol Metab 88: 4440-4445, 2003.

25. Marini F, Falchetti A, Del Monte F, Carbonell Sala S, Tognarini I, Luzi E and Brandi ML: Multiple endocrine neoplasia type 2. Orphanet J Rare Dis 1: 45, 2006.

26. Zhang Y, Wang S, Hu B, Zhao F, Xiang P, Ji D, Chen F, Liu X, Yang F, Wu Y, et al: Direct detection of Helicobacter pylori in biopsy specimens using a high-throughput multiple genetic detection system. Future Microbiol 11: 1521-1534, 2016.

27. Cheng L, Du C, Murray D, Tong X, Zhang YA, Chen BP and Hawley RG: A GFP reporter system to assess gene transfer and expression in human hematopoietic progenitor cells. Gene Ther 4: 1013-1022, 1997.

28. Fischer M, Haase I, Simmeth E, Gerisch $G$ and Müller-Taubenberger A: A brilliant monomeric red fluorescent protein to visualize cytoskeleton dynamics in Dictyostelium. FEBS Lett 577: 227-232, 2004.

29. Kao TH, Chen Y, Pai CH, Chang MC and Wang AH: Structure of a NADPH-dependent blue fluorescent protein revealed the unique role of Gly176 on the fluorescence enhancement. J Struct Biol 174: 485-493, 2011

30. Cissell KA, Rahimi Y, Shrestha S, Hunt EA and Deo SK: Bioluminescence-based detection of microRNA, miR21 in breast cancer cells. Anal Chem 80: 2319-2325, 2008.

This work is licensed under a Creative Commons Attribution-NonCommercial-NoDerivatives 4.0 International (CC BY-NC-ND 4.0) License. 